Abstract

\title{
A Study on The Factor of The Elderly's Maintenance of Employment Status In South Korea
}

Hee-Jeoung Choi1), Kyu-hyoung Jeong2)

This study examined the factors of the elderly's job retention, and it focused on the job retention rather than the reemployment itself which is widely studied before. The data of the study were drawn from Korean Longitudinal Study of Ageing complied by the Korea Employment Information Service from the year 2006 to 2014, and this study analyzed 1,466 people who were over 65 years when conducted in the year 2006. Data were analyzed by SPSS 22.0, and binary logistic regression was conducted to test research model. Analyzed by population sociological, health, economic and institutional factors, the elderly's job retention was affected by gender, age, academic background, period of the partner's existence, depression, gross income of household, total assets of household, period of receiving national basic livelihood guarantees, period of receiving national pension. Based on the results, this study suggests practical and political implication for the elderly's job retention after retirement.

Key word: The Elderly, Job Retention Factors

1) Doctoral Student, School of Social Welfare at Yonsei Univ., Seoul, Korea

2) Doctoral Student, School of Social Welfare at Yonsei Univ., Seoul, Korea 